\title{
The anticancer molecular mechanism of Carnosol in human cervical cancer cells: An in vitro study
}

\author{
Rand R. Hafidh ${ }^{a^{*}}$, Ahmed S. Abdulamir ${ }^{\mathrm{b}}$ \\ ${ }^{a}$ Department of Microbiology, College of Medicine, University of Baghdad, Baghdad, Iraq \\ ${ }^{b}$ Department of Microbiology, College of Medicine, Alnahrain University, Baghdad, Iraq
}

Received 5th April 2020 / Accepted 6th July 2020

\begin{abstract}
Carnosol, a phenolic diterpene, is one of the effective anticancer agents naturally occurring in rosemary, sage, parsley, and oregano. The chemoresistance problem increased with the routinely used chemotherapy. Therefore, the efforts to find a substitute with safe and low cost have become crucial worldwide. The current study attempts to inspect the anticancer molecular mechanisms of Carnosol on modulating up- and down- regulation of multiple genetic carcinogenesis pathways. The cytotoxicity of Carnosol on Hela cells was evaluated by MTS assay. Flow cytometry was used to assess apoptosis and cell cycle arrest. The apoptotic morphological changes were obvious by dual apoptosis assay. The differential gene expression after treatment with Carnosol was investigated by qRT-PCR. Up to $80 \%$ of the treated cells with Carnosol IC50 underwent apoptosis. Apoptosis together with cell cycle arrest in G0/G1 phase were induced significantly after treatment with Carnosol IC50. Fifteen out of nineteen genes studied were found to be remarkably up- or down- regulated after treatment with Carnosol. Six up-regulated genes (EREG, FOS-2, ID2, CRYAB, DUSP5, and TICAM2) and nine down-regulated genes (FN1, KRAS2, CCNB1-1, FEN1, MCM4, MCM5, GTSE1, CXCL1, and RALA) were recorded. These genes are candidates for future research for elucidating anticancer molecular targeted therapies, cancerous signaling and cancer development pathways in cervical cancer; moreover, elucidating the role of apoptosis, inflammation, cell proliferation, and cell differentiation in the development of cervical cancer.
\end{abstract}

Keywords: Carnosol, Hela cells, anticancer molecular therapy, phenolic diterpene, carcinogenesis pathways

\section{INTRODUCTION}

The fourth most common type of cancer among the female population is cervical cancer. It has become a health problem in term of morbidity and mortality worldwide (Pfaffenzeller et al., 2020, Keinan Boker et al., 2020). A recent epidemiological study by the American Cancer Society estimated that mortality rates in low- and middle-income countries were 2 fold higher for cervical cancer during 2012-2016 (Siegel et al., 2019, Keinan Boker et al., 2020).

*Author for correspondence: Rand R. Hafidh, Department of Microbiology, College of Medicine, University of Baghdad, Baghdad, Iraq. Email randriadh@comed.uobaghdad.edu.iq
In Iraq, 244 women are diagnosed with cervical cancer every year and about 159 die from the disease. Moreover, cervical cancer is the $10^{\text {th }}$ most common cancer ranks among women between the age of 15 and 44 years in Iraq (Al-Mussawy, 2019; Alwan, 2017). In contrast, the $3^{\text {rd }}$ most common cancer in Malaysian women is cervical cancer with more than 2,000 records every year and over 600 deaths annually (Seng et al., 2018). The increased incidence of resistant cancer cells along with the high cost of the routinely used 
therapies upsurge the need for a cheap source of therapy. The anticancer activity of different compounds isolated from plants was highlighted by several studies (Hafidh et al., 2018, Hafidh, 2017). Carnosol is a naturally occurring phenolic diterpene, obtained from rosemary, sage, parsley, and oregano; it was shown to have antioxidant and anticarcinogenic properties (Johnson, 2011, de Oliveira et al., 2019). The anticancer property of Carnosol has been evaluated in diverse types of cancers like prostate, breast, skin, leukemia, and colon cancer (Johnson, 2011). The molecular mechanism of the anticancer potential of this phytochemical compound has not yet been fully clarified. For cervical cancer, although many studies were conducted on the gene expression profiling and some of these studies ended with fruitful therapies, yet many molecular target therapies are still in need for this highly malignant cancer. Nineteen genes (IL6, TNF- $a, D D I T 3$, MKI67-2, EREG, FOS-2, ID2, CRYAB, DUSP5, TICAM2, FN1, KRAS2, CCNB1-1, FEN1, MCM4, MCM5, GTSE1, CXCL1, and RALA) were screened to test Carnosol effect on their expression. The chosen genes were shown by previous studies to be related to the development of cervical cancer and other types of cancer (Hao et al., 2020; Babapour et al., 2019; Lin et al., 2018; Clarke et al., 2019; Stintzing et al., 2018; Wang et al., 2019; Mirzaei et al., 2020; Roszik et al., 2018; Ponzio et al., 2017; Kori \& Yalcin Arga, 2018; Slattery et al., 2018; Dun \& Gao, 2019; Li et al., 2019; Kim \& Park, 2014; Zago et al., 2018).

\section{MATERIALS AND METHODS}

\section{The compound and Hela cells preparation}

An absolute dimethyl sulfoxide (DMSO), (BIO BASIC INC., NY, USA) was used to dissolve Carnosol, C9617-5MG, (Sigma, Germany). The stock concentration, $5 \mathrm{mg} / \mathrm{ml}$, was incubated at $20^{\circ} \mathrm{C}$ for further needed analyses. RPMI-1640 medium/ L- glutamine (biowest, Florida, USA) with 10\% fetal bovine serum (Sigma, Germany), $2.5 \mu \mathrm{g} / \mathrm{ml}$ amphotericin B (biowest, Florida, $\mathrm{USA}$ ), and $50 \mathrm{U} / \mathrm{ml}$ penicillin-streptomycin (biowest, Florida, USA) were used to cultivate Human cervix adenocarcinoma cells (Hela cells, ATCC: CCL-2) at $37^{\circ} \mathrm{C}$ with $5 \% \mathrm{CO}_{2}$.

\section{MTS cell viability assay}

The Cell Titer 96 Aqueous One Solution Cell Proliferation Assay (Promega, USA) was used to measure Carnosol-treated cells viability. The viability was measured by MTS $[3-(4,5$ dimethylthiazol-2-yl)-5-(3-

carboxymethoxyphenyl)-2(4-sulfophenyl)-2Htetrazolium] metabolism in active cells. Freshly prepared Carnosol working concentrations of (5, $10,20,40,50$, and $80 \mu \mathrm{g} / \mathrm{ml}$ ) were diluted in $10 \%$ RPMI-1640 medium. Each concentration was used to treat Hela cells $\left(1 \times 10^{5}\right.$ cell/well $)$ with 200 $\mu \mathrm{l} /$ well as a final volume. The plates were incubated for $\left(24,48\right.$, and $72 \mathrm{~h}$ ) in $5 \% \mathrm{CO}_{2}$ at $37^{\circ} \mathrm{C}$. DMSO in $10 \%$ RPMI-1640 medium was used as negative control with the same volume. At the end of the incubation times the wells' contents were replaced with a solution composed of $10 \%$ RPMI-1640 medium (100 $\mu \mathrm{l})$ and MTS (20 $\mu \mathrm{l})$. An ELISA reader (Sunrise Basic Tecan, Grödig, Austria) was used to read the absorbance at 490 $\mathrm{nm}$, after $4 \mathrm{~h}$.

The amount of $50 \%$ killed cells (IC50) by the compound concentration was calculated (Cory et al., 1991).

\section{Cell treatment}

Based on the IC50 value $(50 \mu \mathrm{g} / \mathrm{ml})$ obtained from the MTS assay, $1 \times 10^{5} \mathrm{Hela}$ cell/well were treated with $10 \%$ RPMI-1640 medium with or without Carnosol for $48 \mathrm{~h}$. DMSO in the medium was used as a negative control. After the incubation time was ended, Carnosol-treated Hela cells and untreated control were harvested and washed. The cells were subjected to the following bioassays.

\section{Flow cytometry analysis}

The apoptosis level of cells and cell cycle arrest was analyzed. Ice-cold ethanol $70 \%$ with PBS was used for the fixation of treated and untreated cells $(1: 10 \mathrm{v} / \mathrm{v})$. Incubation was for $2 \mathrm{~h}$ at $-20^{\circ} \mathrm{C}$. Fixed cells were washed by PBS. The following staining DNA solution $(500 \mu \mathrm{l})$ composed of propidium iodide $(25 \mu \mathrm{l})$ as $1 \mathrm{mg} / \mathrm{ml}$ (MP Biomedicals, LLC, IIIKrick, France) and Ribonuclease A (50 $\mu$ l) as 1 $\mathrm{mg} / \mathrm{ml}$ (Sigma, Germany) in PBS was prepared (Siddik, 2010). Measurement was done using CyAn ADP apparatus (BECKMAN COULTER, USA) as triplicates of each sample and control 
(untreated cells). Analysis of the results was completed by the software Summit (V4.3).

\section{A real-time apoptosis detection}

Apoptosis Assay Kit (Dual), NucView ${ }^{\text {TM }} 488$ (Biotium Inc, USA) was used along with caspase3 substrate and sulforhodamine 101 (Texas Red) conjugated Annexin V. It provides two apoptosis events in intact cells in real-time, caspase-3 activity and phosphatidylserine translocation. The procedure followed the manufacturer's instructions and it was as follows: treated and untreated cells were washed with Annexin Vbinding buffer after an aspiration of the wells' contents. Then the following materials were added: $0.2 \mathrm{mM}$ NucView $^{\mathrm{TM}} 488$ caspase-3substrate $(5 \mu \mathrm{L})$, Annexin-binding buffer (100 $\mu \mathrm{L})$, and sulforhodamine 101-annexin $\mathrm{V}(5 \mu \mathrm{L})$ to each well and incubated for 45 minutes. The treated and untreated cells were run as triplicates. Fluorescence microscope (Nikon eclopse 80 i) using FITC and Texas-Red filters, was used to observe the apoptotic events in the stained cells. The apoptotic index has resulted from apoptotic cells' number relative to the total number of cells.

\section{$\boldsymbol{R N A}$ extraction}

Total RNA from the harvested cells (treated and untreated) was isolated according to GF-1 kit (Vivantis Technologies, Malaysia). A concentration of RNA $(546 \mathrm{ng} / \mathrm{ul})$ was measured by Life Science UV/Vis Spectrophotometer (BECKMAN COULTER, USA). The total RNA quality, concentration, purity, and integrity were checked by Agilent 2100 Bioanalyzer (Agilent, USA). The integrity number of total RNA was 8.5. Later, $-80^{\circ} \mathrm{C}$ temperature was used to store the isolated and checked RNA.

\section{Gene expression profile using real-time semi- quantitative RT-PCR}

The cDNA Synthesis Kit (BIO-RAD, Hercules, Canada) was used to convert the isolated RNA from Hela cells $(0.5 \mu \mathrm{g})$ to cDNA. Briefly, a final volume of $20 \mu \mathrm{l}$ per reaction was prepared by mixing $5 \times$ iScript reaction mix $(4 \mu \mathrm{l})$ with iScript reverse transcriptase $(1 \mu \mathrm{l})$ and RNA template (15 $\mu l)$. Thermo Bath (FINEPCR, Seoul, Korea) was used to incubate the prepared mixture for $5 \mathrm{~min}$ at $25^{\circ} \mathrm{C}$ then $30 \mathrm{~min}$ at $42^{\circ} \mathrm{C}$. Later, the temperature of incubation was raised to $85^{\circ} \mathrm{C}$ for
5 min. A temperature $-80^{\circ} \mathrm{C}$ was adjusted to store the prepared cDNA.

The differential expression of the targeted genes was completed using Syber green RT-PCR master mixes (LifeTechnologies, USA) on the iQ5 (Bio-Rad, USA) between treated and untreated Hela cells. Forward and reverse primers' sequence (F: 5-AGAGCTACGAGCTGCCTGAC-3, R: 5AGCACTGTGTTGGCGTACAG-3) of the housekeeping gene $\beta$-actin (ACTB) was used for normalization. The Nineteen primers used to specifically amplify target gene cDNA are shown in (Table 1). The sequence of primers and the pursued cycling regimen for the designed primers was carried out using Primer software (Primer Blast, NIH, USA). According to the specifications entered to the designing utilities software and after in-lab verification of the PCR amplification, the thermal cycling conducted was as follows: one cycle $\left(95^{\circ} \mathrm{C}\right.$ for $\left.180 \mathrm{sec}\right)$ followed with 40 cycles $\left(95^{\circ} \mathrm{C}\right.$ for $60 \mathrm{sec}$, and $60^{\circ} \mathrm{C}$ for $\left.70 \mathrm{sec}\right)$. Quadruplicates of all samples were assayed. Preparation of the negative controls (nonetemplate controls) was done. The differential expression of the housekeeping gene ACTB along with the target genes was measured in folds according to delta-delta $\mathrm{Ct}$ method, known as the $\mathrm{E}^{-\Delta \Delta \mathrm{Ct}}$ method, where $\mathrm{E}$ stands for the value of PCR efficiency calculated out of the efficiency curve. In general, all runs of PCR turned out efficiency $>90 \%$ with $\mathrm{R}^{2}=0.99$. A comparison between the expression levels of untreated controls with treated cells was performed. PCR efficiency for all primers was measured after lowefficiency wells turned out to be zero and calculation of the fold changes in genes expression was carried out.

\section{Analysis of data}

The data was analyzed by using SPSS software version (16.0.0.2) and data were shown as (mean $\pm \mathrm{SD}$ ). The influence of the compound on cell growth inhibition was appraised by using 95\% confidence intervals. Linear regression index equations were used to calculate IC50 value. Student $t$-test was carried out to compare the mean of each cell cycle phase, in triplicates, of treated vs untreated cells in flow cytometric analysis. The calculation of the fold change of genes expression is based on the comparative Ct method in realtime qPCR. The equation for comparative $\mathrm{Ct}$ 
method which is also known as the $2^{-\Delta \Delta C t}$ method was as follows: $\Delta \Delta \mathrm{Ct}=\Delta \mathrm{Ct}$ treated $-\Delta \mathrm{Ct}$ untreated, where: $\Delta \mathrm{Ct}$ treated $=\mathrm{Ct}$ treated - all mean treated and $\Delta \mathrm{Ct}$ untreated $=\Delta \mathrm{Ct}$ untreated - all mean untreated. Less than 0.05 of $p$ values were reflected as significant.

Table 1. Genes names along with their primer sequences used in Real-Time qPCR.

\begin{tabular}{|c|c|c|c|}
\hline Gene Name & Sequence & $\begin{array}{l}\text { Avg. } \\
\text { Tm }\end{array}$ & $\begin{array}{c}\text { Amplicon } \\
\text { size }\end{array}$ \\
\hline IL-6 & F: 5'-CCAGCTATGAACTCCTTCTC-3' & 60 & 413 \\
\hline Interleukin 6 (human) & R: 5'-GCTTGTTCCTCACATCTCTC-3' & & \\
\hline DDIT3 & F: 5'-GAACGGCTCAAGCAGGAAATC-3' & 59.85 & 80 \\
\hline $\begin{array}{l}\text { DNA damage-inducible transcript } 3 \\
\text { (human) }\end{array}$ & R: 5'-T'TCACCAT'TCGGTCAATCAGAG-3' & & \\
\hline MKI67-2 & F: 5'-AATCCAACTCAAGTAAACGGGG-3' & 60 & 245 \\
\hline $\begin{array}{l}\text { marker of proliferation } \mathrm{Ki}-67 \\
\text { (human) }\end{array}$ & R: 5'-T'TGGCT'TGCT'TCCATCCTCA-3' & & \\
\hline TNFA & F:5'-CTCTTCTGCCTGCTGCACT'TTG-3' & 61.1 & 135 \\
\hline Tumor necrosis factor (human) & R:5'-ATGGGCTACAGGCTTGTCACTC-3' & & \\
\hline EREG & F: 5'- GCAGGGATAACAGTGTGCCT-3' & 60 & 547 \\
\hline epiregulin (human) & R: 5'- GACCATAGACTCCCCAGGGT-3' & & \\
\hline FOS-2 & F: 5'- CCCGGACT'TGCACCT'TACT'T-3' & 59.72 & 553 \\
\hline Fos Proto-Oncogene, & R: 5'- ACTGATCTGTCTCCGTCTCCT-3' & & \\
\hline Trancription Factor Subunit (human) & & & \\
\hline DUSP5 & F: 5'- GTGCCTACTGCACATTCCCT-3' & 60 & 288 \\
\hline $\begin{array}{l}\text { dual specificity phosphatase } 5 \\
\text { (human) }\end{array}$ & R: 5'- TCCCGAGAACCTACCCTGAG -3' & & \\
\hline ID2 & F: 5'- ATCCTGTCCTTGCAGGCT'TC -3' & 60.35 & 81 \\
\hline inhibitor of DNA binding 2 (human) & R: 5'- ACCGCT'TATTCAGCCACACA -3' & & \\
\hline TICAM2 & F: 5'- ACAT'TAACCCCTGACTCACAGC -3' & 60.1 & 989 \\
\hline $\begin{array}{l}\text { toll like receptor adaptor molecule } 2 \\
\text { (human) }\end{array}$ & R: 5'- CTCGGGGAAGGGGATTGGTTC -3' & & \\
\hline CRYAB & F: 5'- ACTGCAAGCACCAAGTGTGT -3' & 60.15 & 328 \\
\hline Crystallin Alpha B (human) & R: 5'- GACTCCAACAGGTGCTCTCC -3' & & \\
\hline FN1 & F: 5'-AGCAGACCCAGCTTAGAGTT-3' & 59 & 310 \\
\hline Fibronectin 1 (human) & R: 5'-GCAGAAGTGT'T'TGGGTGACT-3' & & \\
\hline \multirow{2}{*}{ CCNB1 cyclin B1 (human) } & F: 5'- CCTACTGGGTCGGGAAGTCA -3' & 60.3 & 592 \\
\hline & R: 5'- GACTACATTCTTAGCCAGGTGCT-3' & & \\
\hline FEN1 & F: 5'-CAACCCCGAACCAAGCTTTAG-3' & 60 & 634 \\
\hline $\begin{array}{l}\text { Flap structure-specific endonuclease } \\
1 \text { (human) }\end{array}$ & R: 5'- ACACGACCCCATAAGGTGGA-3' & & \\
\hline \multirow{2}{*}{$\begin{array}{l}\text { KRAS } \\
\text { proto-oncogene, GTPase (human) }\end{array}$} & F: 5'- CCCAGGTGCGGGAGAGA -3' & 60.2 & 259 \\
\hline & R: 5'- CCCTCCCCAGTCCTCATGTA -3' & & \\
\hline GTSE1 & F: 5'- ACCAGCAATCTCGCAAGGAA -3' & 59.9 & 503 \\
\hline G2 and S-phase expressed 1 (human) & R: 5'- CGCGAAAGCT'T'TGGTGTTGA -3' & & \\
\hline CXCL1-2 & F: 5'- CTACAGATGCCCATGCCGAT -3' & 60 & 226 \\
\hline $\begin{array}{l}\text { C-X-C Motif Chemokine Ligand } 12 \\
\text { (human) }\end{array}$ & R: 5'- GTGGGTCTAGCGGAAAGTCC -3' & & \\
\hline MCM5 Minichromosome & F: 5'- GCAAGGTTCTCTACCGCCTC -3' & 60 & 352 \\
\hline $\begin{array}{l}\text { maintenance complex component } 5 \\
\text { (human) }\end{array}$ & R: 5'- CAGACCCTGT'TCCCTCACAC -3' & & \\
\hline MCM4 Minichromosome & F: 5'- CT'TTCCACGGTACTCCGAGC -3' & 60.1 & 305 \\
\hline $\begin{array}{l}\text { Maintenance Complex Component } 4 \\
\text { (human) }\end{array}$ & R: 5'- AGTGCCGTATGTCAGTGGTG -3' & & \\
\hline RALA & F: 5'- GATCTCCCCAGAGCAAAGCGT -3' & 60.3 & 229 \\
\hline RAS like proto-oncogene A (human) & R: 5'- TAAGAAGAATCTGCACCGCGA -3' & & \\
\hline
\end{tabular}




\section{RESULTS}

\section{Carnosol cytotoxic effect}

The anti-proliferative effect of Carnosol on human cancer cells was investigated by previous studies and it is in a concentration-dependent manner (Bourhia et al., 2019, Amar et al., 2017).

In the current study, Hela cell viability was reduced by Carnosol treatment in a time- and concentration-dependent manner (Figure 1). The concentration of Carnosol that killed $50 \%$ of Hela cells, or IC50, was $(50 \mu \mathrm{g} / \mathrm{ml})$. This concentration was used in the downstream tests to study the anticancer molecular mechanism of the compound.

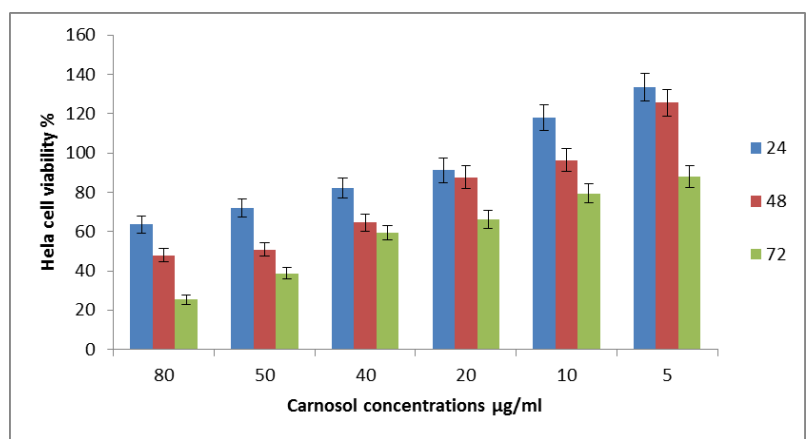

Figure 1. The mean percentages of Hela cells viability after treatment with Carnosol for $(24,48$, and $72 \mathrm{~h}$ ). The viability reduced in a time- and concentration-dependent manner.

\section{Cell-cycle arrest and apoptosis induced by Carnosol}

Carnosol IC50 induced apoptosis and cell-cycle arrest in the treated Hela cells compared to untreated one (Figure 2). Carnosol was observed to promote apoptosis in the treated cells $48 \mathrm{~h}$ after treatment $(24.81 \% \pm 1.26)$ in comparison with untreated cells $(9.61 \% \pm 3.82),(\mathrm{p}=0.002)$. The treated cells were arrested significantly in G0/G1 phase $(62.12 \% \pm 5.83)$ while untreated cells were $(73.75 \% \pm 2.21),(p=0.032)$. On the other hand, the treatment showed non-significant effect on both $\mathrm{S}$ phase and $\mathrm{G} 2 / \mathrm{M}$ phase, $(6.5 \% \pm 1.9)$ in contrast to untreated one $(8.81 \% \pm 3.01),(\mathrm{p}=$ $0.32)$ and $(7.58 \% \pm 3.01)$ in contrast to untreated one $(8.96 \% \pm 1.7),(\mathrm{p}=0.52)$, respectively.

\section{Detection of real-time apoptosis in intact cells} The morphological changes of apoptosis were investigated by fluorescence microscopy to detect the apoptosis induction by Carnosol (Figure 3). The two important apoptosis markers were simultaneously monitored by the kit. The monitored markers were the translocation of phosphatidylserine on the cell membrane (identified by sulforhodamine 101-annexin V) and caspase-3 activation (identified by $\mathrm{NucView}^{\mathrm{TM}}$ 488 caspase- 3 substrate activity) within individual whole cells (Balijepalli et al., 2010). The nucleus stained as a bright green after the cleavage of NucView $^{\text {TM }} 488$ caspase-3 substrate by activated caspase-3 (Figure 3C). Besides, phosphatidylserine that had translocated from the inner to the outer leaflet of the plasma membrane, produced a red border around the cell under a fluorescent microscope using a red filter (Figure 3D).

The morphological changes that could be detected after treatment like detachment, rounding of cells, and cell shrinkage were considered as apoptosis-related events (Desjardins \& MacManus, 1995). A comparison between the treated cells and untreated cells in the negative control plates were done. The Carnosol IC50 $(50 \mu \mathrm{g} / \mathrm{ml})$ induced apoptosis in $80 \%$ of Hela cells after $48 \mathrm{~h}$ of treatment.

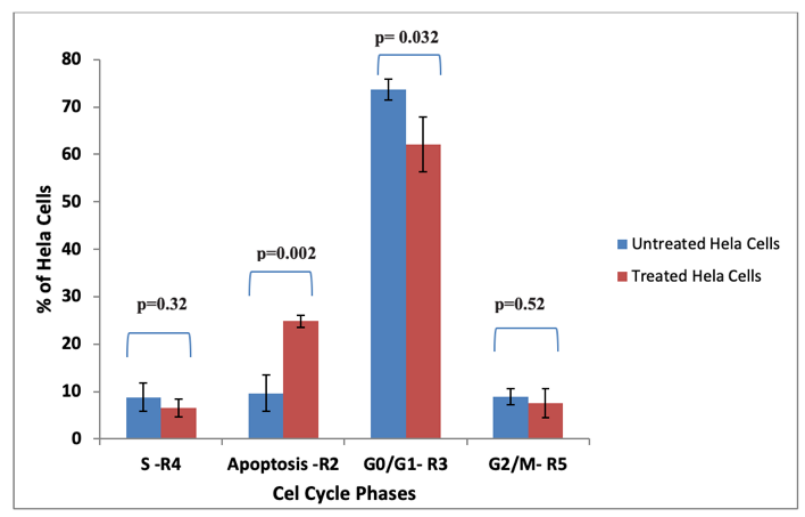

Figure 2. Hela cells DNA content after $48 \mathrm{~h}$ was represented by this histogram of the flow cytometry analysis in untreated cells and treated cells' cultures with Carnosol IC50. Treatment with Carnosol stimulated cell-cycle arrest in G0/G phase and apoptosis. The cells' percentages with fractional DNA content was detected by software CyAn ADP apparatus and Summit (V4.3) program: apoptotic cells (R2), G0/G1 (R3), S (R4), and G2/M (R5) phases. The $\mathrm{p}$ value of less than 0.05 was considered as significant. 

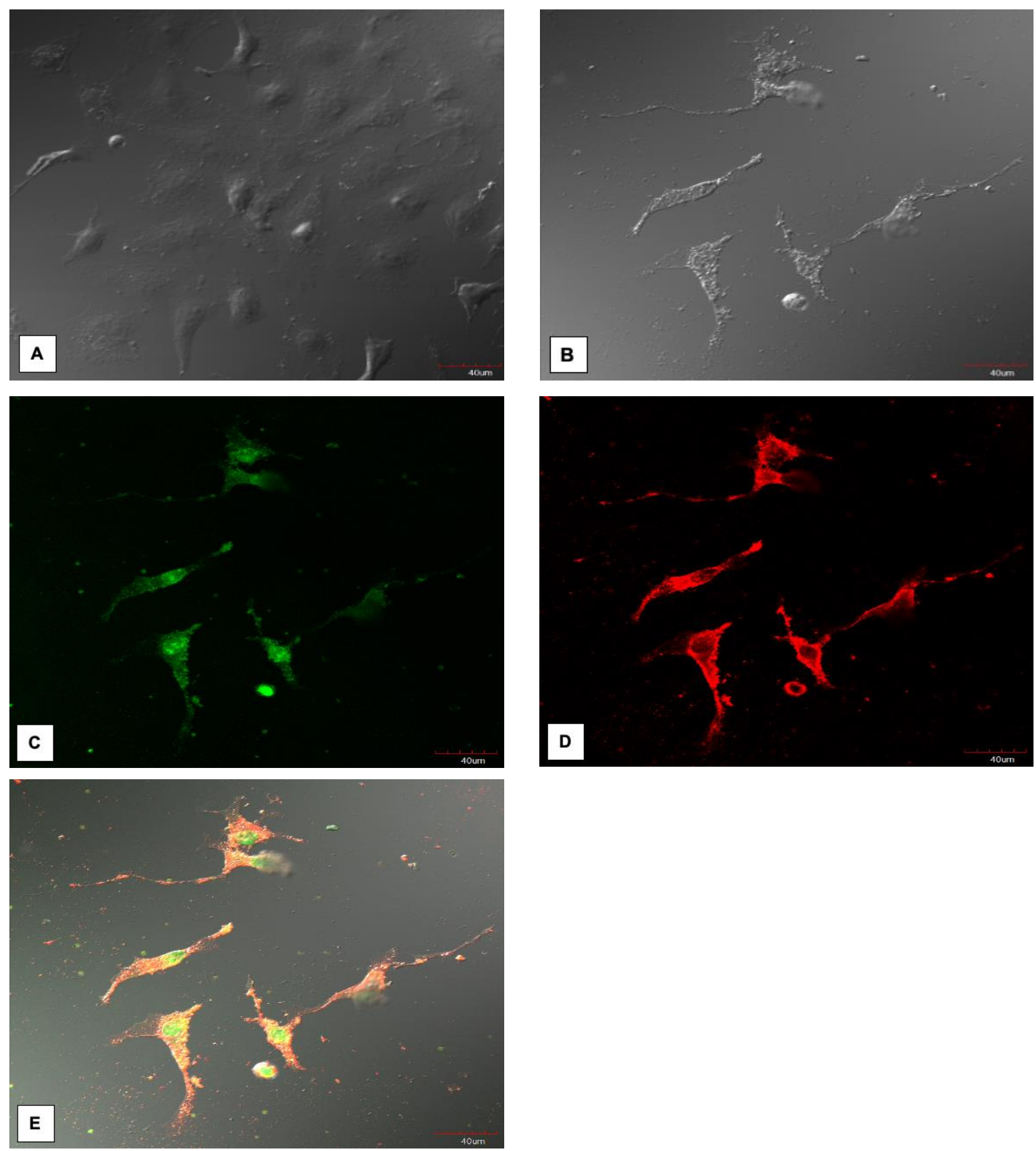

Figure 3. A) The photomicrograph of Hela negative control cell lines showed no morphological changes in these cells. B) The photomicrograph of Hela cell lines treated with Carnosol IC50 $(50 \mu \mathrm{g} / \mathrm{ml})$ for $48 \mathrm{~h}$. The cells viewed under a fluorescent microscope (Nikon eclopse 80 i). The morphological changes were manifested after $48 \mathrm{~h}$ of treatment with Carnosol IC50. C) The photomicrograph of Hela cell lines treated with Carnosol IC50 $(50 \mu \mathrm{g} / \mathrm{ml})$ for $48 \mathrm{~h}$ and stained with caspases-3 substrate. Caspase- 3 activation was indicated by green nuclei in Hela cells. D) The photomicrograph of Hela cell lines treated with Carnosol IC50 $(50 \mu \mathrm{g} / \mathrm{ml})$ for $48 \mathrm{~h}$ and stained with Annexin-V substrate. Phosphatidylserine translocation from inner to the outer leaflet of the cell membrane was indicated as red borders around Hela cells. E) The merged photomicrograph of stained Hela cell lines treated with Carnosol IC50 (50 $\mu \mathrm{g} / \mathrm{ml})$ for $48 \mathrm{~h}$. The apoptotic Hela cells were characterized by green nuclei surrounded by red borders. 


\section{The up- and down-regulation of target genes after Carnosol treatment}

The profile of the gene expression of the treated Hela cells with IC50 of Carnosol for $48 \mathrm{~h}$ was assessed by the semi-quantitative analysis of realtime qPCR. Four genes (IL6, TNF- $a$, DDIT3, and MKI67-2) gave no results neither upregulated nor down-regulated after treatment.

Fifteen genes belong to different carcinogenesis pathways that attributed to cancer progress in human normal cells were shown to be up- or down-regulated after treatment (Table 2).

An immense up-regulation was manifested with EREG gene (13.04 \pm 4.34 folds). On the other hand, immense down-regulation was manifested with FN1 gene (14.05 \pm 4.91 folds). In addition, up-regulation of the following genes was recorded in folds: FOS-2 (9.34 \pm 2.45$)$; ID2 $(6.73 \pm 1.65) ; C R Y A B(5.15 \pm 1.04)$. The rest genes with a significant up-regulation were:

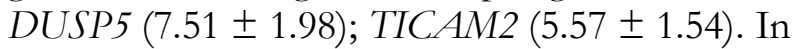
contrast, the genes with a remarkable downregulation in folds were: KRAS2 gene $(9.89 \pm$ 2.52); CCNB1-1 gene (12.37 \pm 3.02$)$; FEN1gene (10.84 \pm 2.56); MCM5 gene (9.42 \pm 2.42); GTSE1 gene $(8.87 \pm 1.59) ; M C M 4$ gene $(7.86 \pm$ 1.43) and $R A L A$ gene $(7.41 \pm 1.15)$.

Table 2. The up- and down-regulation of Hela cells' genes after $48 \mathrm{~h}$ treatment with Carnosol.

\begin{tabular}{|c|c|}
\hline \multicolumn{2}{|c|}{ Expressed genes ${ }^{\text {fold change }}$} \\
\hline Up-regulated & Down-regulated \\
\hline EREG $^{13.04}$ & FN1 ${ }^{14.05}$ \\
\hline FOS $-2^{9.34}$ & CXCL1-2 9.11 \\
\hline$C R Y A B^{5.15}$ & $C C N B 1-1^{12.37}$ \\
\hline ID $2^{6.73}$ & KRAS2 $2^{9.82}$ \\
\hline TICAM2 ${ }^{5.57}$ & $M C M 4^{7.68}$ \\
\hline DUSP5 7.51 & $\mathrm{R} A L A^{7.41}$ \\
\hline & GTSE1 9.24 \\
\hline & MCM5 $5^{8.87}$ \\
\hline & FEN1 10.84 \\
\hline
\end{tabular}

\section{DISCUSSION}

Carnosol anticancer effect has been studied on different cancer cell types (Aliebrahimi et al., 2018; de Oliveira et al., 2019); however, so far, no studies were found on human cervical cancer cell lines. The flow cytometry and the real-time apoptosis assay confirmed the effect of Carnosol IC50 to stimulate apoptosis in $80 \%$ of the treated cells in addition to significant morphological changes. Furthermore, a momentous cell cycle arrest was evident at G0/G1 phase in the treated cells. RT-qPCR analysis was integrated to confirm the anticancer effect of Carnosol IC50 treatment on Hela cells after $48 \mathrm{~h}$.

Treatment didn't show any effect on four genes, namely (IL6, TNF-a, DDIT3, and MKI672) which found to be correlated to cervical cancer development by previous studies. Studies find that the development of different cancers including cervical cancer is related to the proinflammatory cytokines expression like IL-6 (Hao et al., 2020) and TNF-a (Babapour et al., 2019). The overexpression of DDIT3 can act as a promoter for apoptosis in cervical cancer (Lin et al., 2018). The gene MKI67 is considered as a biomarker that could be used to test the susceptibility to develop cervical cancer in human papilloma positive patients (Clarke et al., 2019). The reason behind this unresponsiveness was not clear and need to be evaluated by another study in the future.

Epiregulin (EREG) was highly up-regulated after treatment. Many studies found that recurrent/metastatic head and neck squamous cell carcinoma and colorectal cancer patients with high EREG gene expression, look to benefit more from chemotherapy than those with lower expression (Kogashiwa et al., 2018, Bormann et al., 2019). Unlike high significant downregulation was manifested with Fibronectin 1 gene (FN1) in the current study. This gene has been established to stimulate cell proliferation and migration in different tumors and is upregulated in numerous cancer types (Sun et al., 2020; Song et al., 2020). Additionally, FN1 is upregulated in cervical cancer tissues as detected by Wang et al. (2019). Thus, Carnosol could be used as a therapy to inhibit the development of different cancer types.

Different pathways have been affected by Carnosol treatment in this study. FOS-2 gene also known as activating protein-1 (AP-1) which is responsible for a pathway where deregulation makes the host more vulnerable to cancer development (Mirzaei et al., 2020). This signaling pathway gene was found to be up-regulated by 
the treatment with Carnosol. Similarly, inhibitor of DNA binding 2 (ID2), known as a dominant anti-retinoblastoma (Ponzio et al., 2017) helixloop-helix protein, was found to be up-regulated by the treatment. A previous study found that the down-regulation of this gene is linked with reduced apoptosis and increased cancer cell survival (Luo et al., 2010). Similarly, a study focuses on the fact that multiple epithelialmesenchymal transition-related genes, like ID2 may be potential targets for cervical cancer genetargeted therapy (Roszik et al., 2018).

Recent studies found that alpha B-crystallin (CRYAB), a small heat shock protein that can reduce neuroinflammatory responses, exerts neuroinflammatory mechanisms and plays crucial roles in bone cancer pain (Hang et al., 2020). Moreover, the overexpression of CRYAB in cancer cell lines which was also seen in this study inhibits tumor cell migration and invasion (Ruan et al., 2020) and could be a novel biomarker candidate for a therapy in cervical carcinoma (Kori \& Yalcin Arga, 2018).

Dual specificity phosphatase 5 gene (DUSP5) negatively regulates members of genes that are related to cellular proliferation and differentiation (Youns et al., 2018; Kidger \& Keyse, 2016). The current study was in agreement with other studies that the upregulation of this anticancer gene has attributed to the anticancer molecular effect of the tested natural product on cancer cells (Ponzio et al., 2017).

One of the nuclear factor-kappa B (NFkappaB) signaling pathway genes is the toll-like receptor adaptor molecule 2 (TICAM2) which was shown to be up-regulated after Carnosol treatment. This gene is one of the regulators of an inflammation in the host immune response and that has been associated with the carcinogenic process (Slattery et al., 2018). As several factors are involved in cervical cancer development, including intrinsic factors related to the inflammatory process (Pfaffenzeller et al., 2020) the up-regulation to related genes seems crucial.

KRAS is the most regularly mutated oncogene in $30 \%$ of human neoplasia with many studies tried to develop molecular-targeted therapies for KRAS mutant cancer (Dai et al., 2020; Liu et al., 2019). Carnosol treatment reduced KRAS expression which opens the gate to use it as a potential treatment option for cancer patients with KRAS mutations and blocking KRAS function as highly encouraged by other findings (Chen et al., 2019). A previous study finds that the down-regulation of KRAS can subsequently suppress the proliferation and chemotherapy resistance of cervical cancer cells (Dun \& Gao, 2019).

The down-regulation effect of the investigated genes was in coordination with the arrested cell cycle phase recovered by the analysis of the flow cytometry and apoptosis morphological changes shown by the dual apoptosis assay after treatment with Carnosol. The cyclin B1 gene (CCNB1-1) is a regulatory protein involved in mitosis (Kabir et al., 2018). This gene has been down-regulated markedly after treatment. The down-regulation of this gene inhibits cell line proliferation and growth and induced apoptosis as proofed by another study (Awasthi et al., 2018). Additional genetic downregulation was recorded after treatment with Carnosol; one of the DNA damage repair genes, flap endonuclease 1 (FEN1) was found to be down-regulated. This was a mirror image to the cell cycle arrest at the apoptosis phase induced after treatment with Carnosol; this observation is reported by another study as well (Dong et al., 2019). A study disclosed the fact FEN1 inhibition could increase the sensitivity of cervical cancer cells to radiotherapy ( $\mathrm{Li}$ et al., 2019).

Moreover, the enhanced cell cycle arrest found in this study after treatment with Carnosol was backed by the down-regulation of the replicative helicase proteins (MCM4 and MCM5) which have found to be as enhancers for DNA replication in cervical cancer (Cheng et al., 2017) and cell proliferation promoter in other cancer types (Mio et al., 2016). Similarly, GTSE1 (G2 and $\mathrm{S}$ phase-expressed-1 gene) which is a key regulator of tumor cell migration and metastasis (Penna et al., 2017), was down-regulated in this study. The targeting of this gene in the cervical cancer cell line inhibits culture proliferation as seen by the previous study (Khokhlova et al., 2010).

Moreover, the Carnosol treatment was shown to be effective to reduce the role of the chemokine (C-X-C motif) ligand 1 (CXCL1) in 
the current cancer cells. This inflammatory protein has been stated to be up-regulated in several human cancers (Miyake et al., 2019). This protein is associated with metastasis of cervical cancer cells, thus could be considered as a target therapy of this process (Kim \& Park, 2014).

RALA gene has a crucial role downstream to Ras oncoproteins in human cancers and found to be activated in different cancer types. It is used to be the basis of a novel class of anticancer therapy (Moghadam et al., 2017; Zago et al., 2018). In the current study, the down-regulation of this gene comes in harmony and back up previous studies findings that consider the RALA gene as a target for anticancer therapy.

\section{CONCLUSION}

The anticancer molecular mechanisms of Carnosol have not fully studied so far. Additionally, its anticancer effect on human cervical cancer has not investigated yet. On the other hand, there is an increased incidence of resistance to the most regularly used chemotherapy. This lays urgency to the need for discovering novel anticancer molecular target therapy, taking into consideration the cost and the availability of such therapy. The current study revealed that different genes associated with different signaling pathways were shown to be related to apoptosis, cell differentiation, proliferation, migration, metastasis, regulation of the immune response, and inflammation. These genes were all remarkably affected by the treatment with Carnosol. Moreover, Carnosol was shown to shift gene expression toward the protection against carcinogenesis. This was shown by the collective effect of the up- or down-regulated genes studied in this study. Therefore, we recommend further studies to be done on Carnosol effect on the carcinogenesis of the cervical cancer cells and other types of cancer cells more deliberately.

\section{REFERENCES}

Aliebrahimi, S., Kouhsari, S. M., Arab, S. S., Shadboorestan, A., \& Ostad, S. N. 2018. Phytochemicals, withaferin A and carnosol, overcome pancreatic cancer stem cells as c-Met inhibitors. Biomedicine \& Pharmacotherapy 106: 1527-1536.

Amar, Y., Meddah, B., Bonacorsi, I., Costa, G., Pezzino, G., Saija, A., Cristani, M., Boussahel, S., Ferlazzo, G., \& Meddah, A. T. 2017. Phytochemicals, antioxidant and antiproliferative properties of Rosmarinus officinalis L on U937 and Caco-2 cells. Iranian Journal Of Pharmaceutical Research 16: 315-327.

Awasthi, S., Singhal, S. S., Singhal, J., Nagaprashantha, L., Li, H., Yuan, Y. C., Liu, Z., Berz, D., Igid, H., Green, W. C., Tijani, L., Tonk, V., Rajan, A., Awasthi, Y., \& Singh, S. P. 2018. Anticancer activity of 2'-hydroxyflavanone towards lung cancer. Oncotarget 9: 36202-36219.

Babapour, N., Mehramiz, M., Rastgar Moghadam, A., Behboodi, N., Yousefi, Z., Maftouh, M., Talebian, S., Khazaei, M., Jafarian, A., Sharifi-Sistani, N., Avan, A., \& Hasanzadeh, M. 2019. Association of TNF-308 G>A polymorphism located in tumor necrosis factor a with the risk of developing cervical cancer and results of pap smear. Journal of Cellular Biochemistry 120: 5444-5448.

Balijepalli, M. K., Tandra, S., \& Pichika, M. R. 2010. Antiproliferative activity and induction of apoptosis in estrogen receptor-positive and negative human breast carcinoma cell lines by Gmelina asiatica roots. Pharmacognosy Research 2: 113-9.

Bormann, F., Stinzing, S., Tierling, S., Morkel, M., Markelova, M. R., Walter, J., Weichert, W., Rossner, F., Kuhn, N., Perner, J., Dietz, J., Ispasanie, S., Dietel, M., Schafer, R., Heinemann, V., \& Sers, C. 2019. Epigenetic regulation of amphiregulin and epiregulin in colorectal cancer. International Journal of Cancer 144: 569-581.

Bourhia, M., Laasri, F. E., Aourik, H., Boukhris, A., Ullah, R., Bari, A., Ali, S. S., El Mzibri, M., Benbacer, L., \& Gmouh, S. 2019. Antioxidant and antiproliferative activities of bioactive compounds contained in Rosmarinus Officinalis used in the mediterranean diet. Evidence-Based Complementary And Alternative Medicine 2019: 7623830.

Chen, F., Alphonse, M. P., Liu, Y., \& Liu, Q. 2019. Targeting mutant Kras for anticancer therapy. Current Topics In Medicinal Chemistry 19: 2098-2113.

Cheng, J., Lu, X., Wang, J., Zhang, H., Duan, P., \& Li, C. 2017. Interactome analysis of gene expression profiles of cervical cancer reveals dysregulated mitotic gene clusters. American Journal of Translational Research 9: 3048-3059.

Clarke, M. A., Cheung, L. C., Castle, P. E., Schiffman, M., Tokugawa, D., Poitras, N., Lorey, T., Kinney, W., \& Wentzensen, N. 2019. Five-year risk of cervical precancer following P16/Ki-67 dual-stain triage of HPV-positive women. Jama Oncology 5: 181-186.

Cory, A. H., Owen, T. C., Barltrop, J. A., \& Cory, J. G. 1991. Use of an aqueous soluble tetrazolium/formazan assay for cell growth assays in culture. Cancer Communications 3: 207-12.

Dai, E., Han, L., Liu, J., Xie, Y., Kroemer, G., Klionsky, D. J., Zeh, H. J., Kang, R., Wang, J., \& Tang, D. 2020. Autophagy-dependent ferroptosis drives tumor-associated macrophage polarization via release and uptake of oncogenic Kras protein. Autophagy: 1-15.

De Oliveira, J. R., Camargo, S. E. A., \& De Oliveira, L. D. 2019. Rosmarinus Officinalis L. (Rosemary) as therapeutic and prophylactic agent. Journal of Biomedical Science 26: 5.

Desjardins, L. M. \& Macmanus, J. P. 1995. An adherent cell model to study different stages of apoptosis. Experimental Cell Research 216: 380-7.

Dong, S., Xiao, Y., Ma, X., He, W., Kang, J., Peng, Z., Wang, L., \& Li, Z. 2019. miR-193b increases the chemosensitivity of osteosarcoma cells by promoting FEN1-mediated autophagy. Oncotargets and Therapy 12: 10089-10098.

Dun, S. \& Gao, L. 2019. Tanshinone I attenuates proliferation and chemoresistance of cervical cancer in a Kras- 
dependent manner. Journal of Biochemical and Molecular Toxicology 33: E22267.

Hafidh, R. R. 2017. A comprehensive anticancer molecular study for genistein the promising anticancer drug. Journal of Contemporary Medical Sciences 3: 264-269.

Hafidh, R. R., Hussein, S. Z., Malallah, M. Q., Abdulamir, A. S., \& Abu Bakar, F. 2018. A high-throughput quantitative expression analysis of cancer-related genes in human HepG2 cells in response to limonene, a potential anticancer agent. Current Cancer Drug Targets 18: 807-815.

Hang, L. H., Chen, H. M., Yu, J. M., Xu, Y., \& Li, S. N. 2020. Evidence of the involvement of spinal alphaB-crystallin in the maintenance of bone cancer pain in rats. Pharmacological Reports 72: 208-213.

Hao, Y., Yan, Z., Zhang, A., Hu, S., Wang, N., Luo, X. G., Ma, W., Zhang, T. C., \& He, H. 2020. IL-6/STAT3 mediates the HPV18 E6/E7 stimulated upregulation of MALAT1 gene in cervical cancer hela cells. Virus Research 281: 197907.

Al-Mussawy, J. J., Al-Faisal, A. H. M., Al-Ahmer, S. D., Qasim, A. 2019. Impact of age factor in cervical abnormalities and cancers incidence in some Iraqi married women. Iraqi Journal Of Biotechnology 18: 58-66.

Johnson, J. J. 2011. Carnosol: A promising anti-cancer and antiinflammatory agent. Cancer Letters 305: 1-7.

Kabir, M. F., Mohd Ali, J., \& Haji Hashim, O. 2018. Microarray gene expression profiling in colorectal (HCT116) and hepatocellular (HepG2) carcinoma cell lines treated with Melicope ptelefolia leaf extract reveals transcriptome profiles exhibiting anticancer activity. Peerj - The Journal of Life and Environmental Sciences 6: E5203.

Keinan Boker, L., Twig, G., Klaitman-Meir, V., Derazne, E., Shina, A., Levine, H., \& Kark, J. D. 2020. Adolescent characteristics and incidence of pre-malignant disease and invasive tumors of the cervix. The International Journal of Gynecological Cancer.

Khokhlova, E. V., Shkoporov, A. N., Volodin, N. N., Efimov, B. A., Pavlov, K. A., \& Kafarskaia, L. I. 2010. Relationship between suppression of E6 and E7 virus oncogenes and expression of apoptosis and cell cycle genes in cervical cancer culture. Bulletin Of Experimental Biology and Medicine 149: 73-7.

Kidger, A. M. \& Keyse, S. M. 2016. The regulation of oncogenic RAS/ERK signalling by dual-specificity mitogen activated protein kinase phosphatases (MKPs). Seminars in Cell and Developmental Biology 50: 125-32.

Kim, B. \& Park, B. 2014. Baohuoside I suppresses invasion of cervical and breast cancer cells through the downregulation of CXCR4 chemokine receptor expression. Biochemistry 53: 7562-9.

Kogashiwa, Y., Inoue, H., Kuba, K., Araki, R., Yasuda, M., Nakahira, M., \& Sugasawa, M. 2018. Prognostic role of epiregulin/amphiregulin expression in recurrent/metastatic head and neck cancer treated with cetuximab. Head Neck 40: 2424-2431.

Kori, M. \& Yalcin Arga, K. 2018. Potential biomarkers and therapeutic targets in cervical cancer: insights from the meta-analysis of transcriptomics data within network biomedicine perspective. PLOS One 13: E0200717.

Li, J. L., Wang, J. P., Chang, H., Deng, S. M., Du, J. H., Wang, X. X., Hu, H. J., Li, D. Y., Xu, X. B., Guo, W. Q., Song, Y. H., Guo, Z., Sun, M. X., Wu, Y. W., \& Liu, S. B. 2019. FEN1 inhibitor increases sensitivity of radiotherapy in cervical cancer cells. Cancer Medicine 8: 7774-7780.

Lin, C. L., Lee, C. H., Chen, C. M., Cheng, C. W., Chen, P. N., Ying, T. H., \& Hsieh, Y. H. 2018. Protodioscin induces apoptosis through ROS-Mediated endoplasmic reticulum stress via the JNK/P38 activation pathways in human cervical cancer cells. Cellular Physiology and Biochemistry 46: 322-334.

Liu, P., Wang, Y. \& Li, X. 2019. Targeting the untargetable kras in cancer therapy. Acta Pharmaceutica Sinica B 9: 871-879.

Luo, K. L., Luo, J. H., \& Yu, Y. P. 2010. (-)-epigallocatechin-3gallate induces DU145 prostate cancer cell death via downregulation of inhibitor of DNA binding 2, a dominant negative helix-loop-helix protein. Cancer Science 101: 707-12.

Mio, C., Lavarone, E., Conzatti, K., Baldan, F., Toffoletto, B., Puppin, C., Filetti, S., Durante, C., Russo, D., Orlacchio, A., Di Cristofano, A., Di Loreto, C., \& Damante, G. 2016. MCM5 as a target of bet inhibitors in thyroid cancer cells. Endocrine-Related Cancer 23: 335-47.

Mirzaei, H., Khodadad, N., Karami, C., Pirmoradi, R., \& Khanizadeh, S. 2020. The AP-1 Pathway; a key regulator of cellular transformation modulated by oncogenic viruses. Reviews In Medical Virology 30: E2088.

Miyake, M., Furuya, H., Onishi, S., Hokutan, K., Anai, S., Chan, O., Shi, S., Fujimoto, K., Goodison, S., Cai, W., \& Rosser, C. J. 2019. Monoclonal antibody against CXCL1 (HL2401) as a novel agent in suppressing IL6 expression and tumoral growth. Theranostics 9: 853-867.

Moghadam, A. R., Patrad, E., Tafsiri, E., Peng, W., Fangman, B., Pluard, T. J., Accurso, A., Salacz, M., Shah, K., Ricke, B., Bi, D., Kimura, K., Graves, L., Najad, M. K., Dolatkhah, R., Sanaat, Z., Yazdi, M., Tavakolinia, N., Mazani, M., Amani, M., Ghavami, S., Gartell, R., Reilly, C., Naima, Z., Esfandyari, T., \& Farassati, F. 2017. RA1 signaling pathway in health and cancer. Cancer Medicine 6: 2998-3013.

Alwan, N. A., Al-Attar, W. M., Al-Mallah, N., \& Abdulla, K. N. 2017. Assessing the knowledge, attitude and practices towards cervical cancer screening among a sample of iraqi female population. Iraqi Journal of Biotechnology 16: 38-47.

Penna, I., Gigoni, A., Costa, D., Vella, S., Russo, D., Poggi, A., Villa, F., Brizzolara, A., Canale, C., Mescola, A., Daga, A., Russo, C., Nizzari, M., Florio, T., Menichini, P., \& Pagano, A. 2017. The inhibition of $45 \mathrm{~A}$ ncRNA expression reduces tumor formation, affecting tumor nodules compactness and metastatic potential in neuroblastoma cells. Oncotarget 8: 8189-8205.

Pfaffenzeller, M. S., Franciosi, M. L. M., \& Cardoso, A. M. 2020. Purinergic signaling and tumor microenvironment in cervical cancer. Purinergic Signalling.

Ponzio, G., Rezzonico, R., Bourget, I., Allan, R., Nottet, N., Popa, A., Magnone, V., Rios, G., Mari, B. \& Barbry, P. 2017. A new long noncoding RNA (lncRNA) is induced in cutaneous squamous cell carcinoma and down-regulates several anticancer and cell differentiation genes in mouse. The Journal of Biological Chemistry 292: 12483-12495.

Roszik, J., Ring, K. L., Wani, K. M., Lazar, A. J., Yemelyanova, A. V., Soliman, P. T., Frumovitz, M. \& Jazaeri, A. A. 2018. Gene expression analysis identifies novel targets for cervical cancer therapy. Frontiers In Immunology 9: 2102.

Ruan, H., Li, Y., Wang, X., Sun, B., Fang, W., Jiang, S., \& Liang, C. 2020. CRYAB inhibits migration and invasion of bladder cancer cells through the PI3K/AKT and ERK pathways. Japanese Journal of Clinical Oncology 50: 254-260.

Seng, L. M., Rosman, A. N., Khan, A., Haris, N. M., Mustapha, N. A. S., Husaini, N. S. M., \& Zahari, N. F. 2018. Awareness of cervical cancer among women in Malaysia. International Journal of Health Sciences 12: 42-48.

Siddik, Z. H. 2010. Checkpoint Controls And Targets In Cancer Therapy, Totowa, N.J., Humana Press.

Siegel, R. L., Miller, K. D., \& Jemal, A. 2019. Cancer statistics, 2019. Ca: A Cancer Journal for Clinicians 69: 7-34.

Slattery, M. L., Mullany, L. E., Sakoda, L., Samowitz, W. S., Wolff, R. K., Stevens, J. R., \& Herrick, J. S. 2018. The NF- 
KappaB signalling pathway in colorectal cancer: associations between dysregulated gene and miRNA expression. Journal of Cancer Research and Clinical Oncology 144: 269-283.

Song, Y., Gao, F., Peng, Y. \& Yang, X. 2020. Long non-coding RNA DBH-AS1 promotes cancer progression in diffuse large B-cell lymphoma by targeting FN1 via RNA-binding protein BUD13. Cell Biology International.

Stintzing, S., Ivanova, B., Ricard, I., Jung, A., Kirchner, T., Tannapfel, A., Juette, H., Hegewisch-Becker, S., Arnold, D., \& Reinacher-Schick, A. 2018. Amphiregulin (AREG) and epiregulin (EREG) gene expression as predictor for overall survival (OS) in oxaliplatin/fluoropyrimidine plus bevacizumab treated $\mathrm{mCRC}$ patients-analysis of the phase III AIO KRK-0207 trial. Frontiers In Oncology 8: 474.

Sun, Y., Zhao, C., Ye, Y., Wang, Z., He, Y., Li, Y., \& Mao, H. 2020. High expression of fibronectin 1 indicates poor prognosis in gastric cancer. Oncology Letters 19: 93-102.

Wang, S., Gao, B., Yang, H., Liu, X., Wu, X., \& Wang, W. 2019. MicroRNA-432 is downregulated in cervical cancer and directly targets FN1 to inhibit cell proliferation and invasion. Oncology Letters 18: 1475-1482.

Youns, M., Elkhoely, A., \& Kamel, R. 2018. The growth inhibitory effect of gambogic acid on pancreatic cancer cells. Naunyn Schmiedebergs Archives Of Pharmacolog 391: 551560.

Zago, G., Veith, I., Singh, M. K., Fuhrmann, L., De Beco, S., Remorino, A., Takaoka, S., Palmeri, M., Berger, F., Brandon, N., El Marjou, A., Vincent-Salomon, A., Camonis, J., Coppey, M., \& Parrini, M. C. 2018. RalB directly triggers invasion downstream Ras by mobilizing the wave complex. Elife, 7. 